\title{
Stereoselective biotransformation of racemic mandelic acid using immobilized laccase and (S)-mandelate dehydrogenase
}

\author{
Xing Chen, Chengli Yang, Peng Wang, Xuan Zhang, Bingxin Bao, Dali Li and Ruofu Shi
}

\begin{abstract}
Objectives: (S)-Mandelate dehydrogenase (SMDH) and laccase were immobilized on chitosan. The bi-enzymatic system with immobilized SMDH and immobilized laccase was taken to catalyze the stereoselective transformation of racemic mandelic acid and (R)-mandelic acid was obtained from its racemic mixture.

Results: Characteristics of the immobilized enzymes were valuated. The optimum $\mathrm{pH}$ and temperature of the immobilized SMDH were found to be $\mathrm{pH} 3.4$ and $45^{\circ} \mathrm{C}$, and these of the immobilized laccase were about $\mathrm{pH} 6.0$ and $55^{\circ} \mathrm{C}$, respectively. The $K_{m}$ value of the immobilized $\mathrm{SMDH}$ for racemic mandelic acid was $0.27 \mathrm{mM}$ and that of the immobilized laccase for ferrocyanide was $0.99 \mathrm{mM}$. The thermal and storage stabilities of these enzymes were improved with immobilization. The enantiomeric purity of the bi-enzymatically produced (R)-mandelic acid was determined to be over $99 \%$.
\end{abstract}

Conclusion: The immobilized bi-enzymatic system for the stereoselective transformation of racemic mandelic acid showed higher productivity, faster reaction velocity, and more stable catalytic ability.

Keywords: Biocatalysis, (S)-Mandelate dehydrogenase, Laccase, Immobilization, Chitosan, Bi-enzymatic system

\section{Background}

Mandelic acid (MA) was an important drug intermediate and can be large-scalely produced at a relatively low cost by chemical synthesis (Huang and Xu 2006; Lorenz et al. 2002; Tulashie et al. 2010). However, there was an increasing demand for the separation of racemic compound into its chiral constituents in the pharmaceuti$\mathrm{cal}$ and biochemical industries due to the recognition of differences in pharmacological activity of enantiomeric molecules (Mao et al. 2012). (R)-Mandelic acid (R-MA) was a useful chiral material for the production of pharmaceuticals, such as semisynthetic penicillins, cephalosporins, antitumor agents, and antiobesity agents $(\mathrm{He}$ et al. 2008; Takahashi et al. 1995). R-MA can be produced by physicochemical methods and biotransformation (He et al. 2008). For example, R-MA can be effectively

\footnotetext{
*Correspondence: lidali@njust.edu.cn

Department of Bioengineering, Nanjing University of Science

and Technology, Xiaolingwei 200, Nanjing 210094,

People's Republic of China
}

produced using mandelonitrile as the substrate by the nitrilase (Zhang et al. 2010, 2014). Using racemic mandelic acid as a raw material for the production of R-MA by biocatalysis would be another beneficial and important strategy.

FMN-dependent (S)-mandelate dehydrogenase (SMDH) (EC 1.1.99.31) specially oxidized (S)-mandelic acid (S-MA) to benzoylformic acid (BA) while the cofactor FMN was reduced to $\mathrm{FMNH}_{2}$ (Dewanti and Mitra 2003). R-MA can be obtained through stereoselective transformation of racemic mandelic acid, in which S-MA was selectively consumed by SMDH and R-MA was leaved in the reaction system. However, the regeneration of cofactors was usually the main difficulty for the applications of flavin-containing dehydrogenases (Blank et al. 2010). Fortunately, FMN can be regenerated in vitro by laccase when using ferrocyanide as the redox mediator (Baminger et al. 2001). Laccase (EC 1.10.3.2) was a copper-containing phenol oxidase and can oxidate ferrocyanide to ferricyanide, while oxygen was concomitantly 
reduced to water (Ludwig et al. 2004; Thurston 1994). SMDH and laccase may operate concurrently in one pot to overcome the limitations and disadvantages of a multistep cascade involving reduction and oxidation. In the previous research, a bi-enzymatic system based on coupling SMDH and laccase for the production of R-MA was constructed successfully (Wang et al. 2013). In the bi-enzymatic system, the SMDH catalyzed the oxidation of S-MA to BA and FMN was concomitantly reduced to $\mathrm{FMNH}_{2}$, and then $\mathrm{FMN}$ was regenerated through the reduction of ferricyanide; the reduced ferricyanide was continuously reoxidized by laccase catalysis. Therefore, the bi-enzymatic system continuously catalyzed the stereoselective transformation of MA and R-MA was obtained from the racemic mixture. Nevertheless, because the free enzymes were put in dialysis bags and were easily inactivated, there was mass transfer limitation in the reaction system, and it limited the further industrial applications of the bi-enzymatic system.

Enzyme immobilization technology was an effective means to benefit the reuse of enzyme and its stability. Immobilization not only enhanced enzyme properties but also facilitated the separation of products. A common method of enzyme immobilization was the covalent linkage of the enzyme to polymeric materials, like chitosan (Silva et al. 2012). Enzyme immobilization on chitosan not only enhanced the chances for reuse but also provided a nontoxic and biocompatible microenvironment conducive to the catalytic activity and stability of the enzyme (Kaur et al. 2014). Like most water-soluble enzymes, the immobilization of SMDH and laccase was a prerequisite for its practical application ( $\mathrm{Li}$ et al. 2013). In the past three or four decades, immobilization technology has developed rapidly and many kinds of enzymes including laccase have been successfully immobilized on chitosan for biocatalytic reaction (Delanoy et al. 2005; Jiang et al. 2005), and the immobilization of SMDH has also been studied recently and its stability was improved compared to the free counterpart (Wang et al. 2014).

In this study, the SMDH and laccase were immobilized by the strategy that amino groups of enzyme molecules and chitosan were combined through Schiff base linkage by glutaraldehyde. Some enzymatic properties of immobilized SMDH and immobilized laccase, such as optimal $\mathrm{pH}$, optimal temperature, and $K_{\mathrm{m}}$ value, were studied. In addition, the improved bi-enzymatic system consisting of immobilized SMDH and immobilized laccase catalyzed continuously the stereoselective transformation of MA and R-MA was obtained from its racemic mixture (Fig. 1).

\section{Methods}

\section{Chemicals}

All chemicals used in this study were of the highest grade available and were obtained from Sinopharm Chemical Reagent (Nanjing, China). Toyopearl DEAE-650 M and butyl-Toyopearl $650 \mathrm{M}$ were obtained from Tosoh (Osaka, Japan). Chitopearl BCW-2605 and Chitopearl BCW-2503 (chitosan beads) were purchased from Fujibo (Tokyo, Japan).

\section{The preparation of SMDH and laccase}

The SMDH was produced from the recombinant Escherichia coli and the laccase was produced from the fruit bodies of Agaricus bisporus as previously described<smiles>O=C(O)[C@H](O)c1ccccc1</smiles>

(S)-mandelic acid<smiles>O=C(O)C(=O)c1ccccc1</smiles>

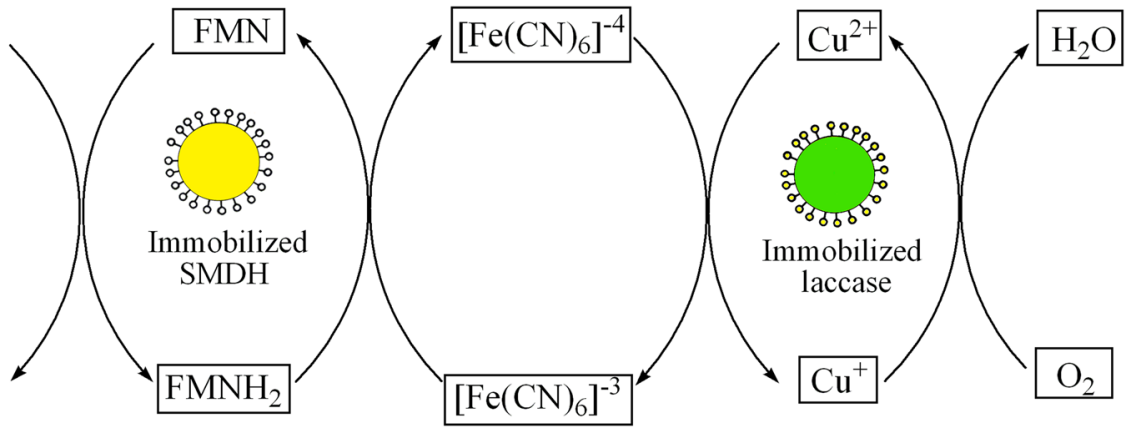

benzoylformic acid

Fig. 1 Bi-enzymatic system with immobilized SMDH and immobilized laccase catalyzed continuously the transformation of (S)-mandelic acid to benzoylformic acid using ferricyanide/ferrocyanide as the redox medium 
(Wang et al. 2013). The preparation of SMDH used throughout this study was partially purified by a singleanion exchange chromatography step using a Toyopearl DEAE-650 M column with a linear $\mathrm{NaCl}$ gradient $(0-3.0 \mathrm{M})$ elution at a flow rate of $1.0 \mathrm{~mL} / \mathrm{min}$. On average, $4.9 \mathrm{U} / \mathrm{mL}$ of SMDH was produced, corresponding to a specific activity of $20.5 \mathrm{U} / \mathrm{mg}$. The laccase was partially purified by a single-anion exchange chromatography step using a Toyopearl DEAE-650 M column with a linear $\mathrm{NaCl}$ gradient $(0-3.0 \mathrm{M})$ elution, and then using a butylToyopearl $650 \mathrm{M}$ column with a linear ammonium sulfate gradient (saturation of 30-0\%) elution at a flow rate of $1.0 \mathrm{~mL} / \mathrm{min}$. After removing the ammonium sulfate by dialysis, $2.5 \mathrm{U} / \mathrm{mL}$ laccase was obtained, corresponding to a specific activity of $2.36 \mathrm{U} / \mathrm{mg}$.

\section{Enzyme activity assay}

The SMDH activity was assayed by measuring the decrease in absorbance of ferricyanide with a U-1800 spectrophotometer at $420 \mathrm{~nm}$ as described in the previous study (Wang et al. 2014). One unit of SMDH activity was defined as the amount of enzyme reducing $1 \mu \mathrm{mol}$ of potassium ferricyanide per minute under the above reaction conditions. The free or immobilized laccase activity was assayed at $30{ }^{\circ} \mathrm{C}$ by following the increase in the absorbance of potassium ferricyanide at $420 \mathrm{~nm}$ in $200 \mathrm{mM} \mathrm{Na}_{2} \mathrm{HPO}_{4}$-citric acid buffer (pH 6.0) consisting of $20 \mathrm{mM}$ potassium ferrocyanide. One unit of the laccase activity was defined as the amount of enzyme increasing $1 \mu \mathrm{mol}$ of potassium ferricyanide per minute under the above reaction conditions (Kurokawa et al. 2010).

\section{Immobilization on chitosan}

The chitosan merchandise Chitopearl BCW-2605 was used as the support for the immobilization of SMDH and Chitopearl BCW-2503 was used for immobilization of laccase. $4.0 \mathrm{~g}$ of chitosan beads were suspended in $50 \mathrm{~mL}$ of $5 \%(\mathrm{v} / \mathrm{v})$ glutaraldehyde, and the mixture was kept on a rotary shaking incubator for $90 \mathrm{~min}$ at $25^{\circ} \mathrm{C}$. Finally, the supports were washed with deionized water to remove unbound glutaraldehyde.

Immobilization of SMDH and laccase were carried out by mixing enzymes with the previously activated supports on a rotary shaking incubator for $90 \mathrm{~min}$ at $25^{\circ} \mathrm{C}$. The activated supports were used for immobilization of $20 \mathrm{~mL} \mathrm{SMDH}$ and $25 \mathrm{~mL}$ laccase, respectively. The initial enzyme activity of supernatant was taken as $100 \%$. The immobilization yield (IY) could be calculated according to Eq. (1), where $A$ was the initial activity in the supernatant and $B$ was the activity of the immobilized enzyme:

$$
\operatorname{IY}(\%)=\frac{B}{A} \times 100 \text {. }
$$

\section{Studies on the enzymatic properties}

The effects of $\mathrm{pH}$ on free and immobilized laccase activities were performed in $10.0 \mathrm{~mL} \mathrm{Na}_{2} \mathrm{HPO}_{4}$-citric acid buffer $(200 \mathrm{mM}, \mathrm{pH} 2.2-8.0)$ containing $20 \mathrm{mM}$ potassium ferrocyanide at $55^{\circ} \mathrm{C}$. The effects of temperature on free and immobilized laccase activities were performed in $10.0 \mathrm{~mL} \mathrm{Na}_{2} \mathrm{HPO}_{4}$-citric acid buffer (200 mM, pH 6.0) containing $20 \mathrm{mM}$ potassium ferrocyanide, and the reaction systems were treated at different temperatures for 15 min before enzymes were put into. The Michaelis constant $\left(K_{\mathrm{m}}\right)$ of laccase (immobilized and free) for ferrocyanide was determined using Lineweaver-Burk method at their optimal $\mathrm{pH}$ and temperature.

\section{The thermal stability and storage stability assay}

The SMDH-Chitopearl BCW-2605 and laccase-Chitopearl BCW-2503 were separated from the supernatant by filtration, and then were washed with deionized water. Immobilized SMDH and laccase were subjected to thermal stability in $\mathrm{Na}_{2} \mathrm{HPO}_{4}$-citric acid buffer $(200 \mathrm{mM}$, pH 6.0) at their optimal temperatures for $200 \mathrm{~h}$, and were subjected to storage stability in the same buffer at $4{ }^{\circ} \mathrm{C}$. The control experiment was performed with the free enzymes. Samples were withdrawn periodically and their residual activities were measured to evaluate the thermal stability and storage stability. The initial activity was taken as $100 \%$.

\section{The bi-enzymatic system consisting of immobilized SMDH and immobilized laccase catalyzed the stereoselective transformation of mandelic acid}

The stereoselective transformation of MA was aerobically catalyzed by the coupling of immobilized SMDH and immobilized laccase with ferricyanide or ferrocyanide as the redox mediator. The experiment was performed at $30{ }^{\circ} \mathrm{C}$ and was oxygenated by incubating on a rotary shaking incubator $(140 \mathrm{rpm})$ in $150 \mathrm{~mL}$ beakers. The reaction system contained $10 \mathrm{mM}$ potassium ferrocyanide, $1.0 \mathrm{~g}$ immobilized SMDH, $1.0 \mathrm{~g}$ immobilized laccase, and MA with concentrations of $10,20,30,40,50$, and $60 \mathrm{mM}$ in $50 \mathrm{~mL} \mathrm{Na} \mathrm{HPO}_{4}$-citric acid buffer (200 mM, pH 6.0). At fixed intervals, $10 \mu \mathrm{L}$, the reaction mixture was withdrawn to monitor the course of the reaction by highperformance liquid chromatography (HPLC), which has been described in our previous description (Wang et al. 2014, 2013). When the concentration of MA was optimized in the reaction system, the stereoselective transformation and reuse of the bi-enzymatic system were conducted under the same conditions.

\section{Analytical methods}

MA and BA were analyzed by HPLC using a $\mathrm{C}_{18}$ column (VP-ODS, $150 \mathrm{~mm} \times 4.6 \mathrm{~mm}$, Shimadzu, Japan) at $25^{\circ} \mathrm{C}$. 
They were detected at $220 \mathrm{~nm}$ with a Shimadzu SPD-10A detector. The mobile phase consisted of methanol and phosphate buffer $\left(6.6 \mathrm{~g} / \mathrm{L} \mathrm{Na}_{2} \mathrm{HPO}_{4}, 6.8 \mathrm{~g} / \mathrm{L} \mathrm{KH}_{2} \mathrm{PO}_{4}\right)$ $(1: 9, \mathrm{v} / \mathrm{v})$, and the flow rate was $1.0 \mathrm{~mL} / \mathrm{min}$.

The (S)-mandelic acid and the (R)-mandelic acid were analyzed by HPLC using a chiral column $(\gamma-\mathrm{CD}$, $150 \mathrm{~mm} \times 4.6 \mathrm{~mm}$, YMC, Japan) at $25{ }^{\circ} \mathrm{C}$. They were detected at $254 \mathrm{~nm}$ with a Shimadzu SPD-10A detector. The mobile phase consisted of phosphate buffer $(6.6 \mathrm{~g} / \mathrm{L}$ $\left.\mathrm{Na}_{2} \mathrm{HPO}_{4}, 6.8 \mathrm{~g} / \mathrm{L} \mathrm{KH}_{2} \mathrm{PO}_{4}\right)$, ethanol, and acetonitrile $(65: 20: 15, \mathrm{v} / \mathrm{v})$, and the flow rate was $1.0 \mathrm{~mL} / \mathrm{min}$.

\section{Results and discussion Immobilization}

The immobilization of SMDH and laccase on glutaraldehyde-activated chitosan beads was studied. The results were shown at Fig. 2. It was found that $1.2 \mathrm{~g}$ support was the optimal support content for both $5.0 \mathrm{~mL} \mathrm{SMDH}$ and laccase immobilization. After calculation, the immobilization yield for SMDH was $62.69 \%$ and that for laccase was $62.4 \%$; the activity of immobilized SMDH was $12.8 \mathrm{U} / \mathrm{g}$ and that of immobilized laccase was $6.5 \mathrm{U} / \mathrm{g}$. The behavior of high immobilization yield and immobilized enzyme activity may be explained by the fact that the strategy of immobilization was appropriate and the amine groups in chitosan have been highly activated with glutaraldehyde, and amine groups of the proteins were easy to link with glutaraldehyde-activated chitosan.

\section{Enzymatic properties}

The effects of $\mathrm{pH}$ on the activity of free and immobilized laccase for the oxidation of ferrocyanide were studied, and the results were presented in Fig. 3. The free laccase showed an optimum $\mathrm{pH}$ of 3.0 and the optimum $\mathrm{pH}$ of immobilized laccase was 6.0, and the immobilized

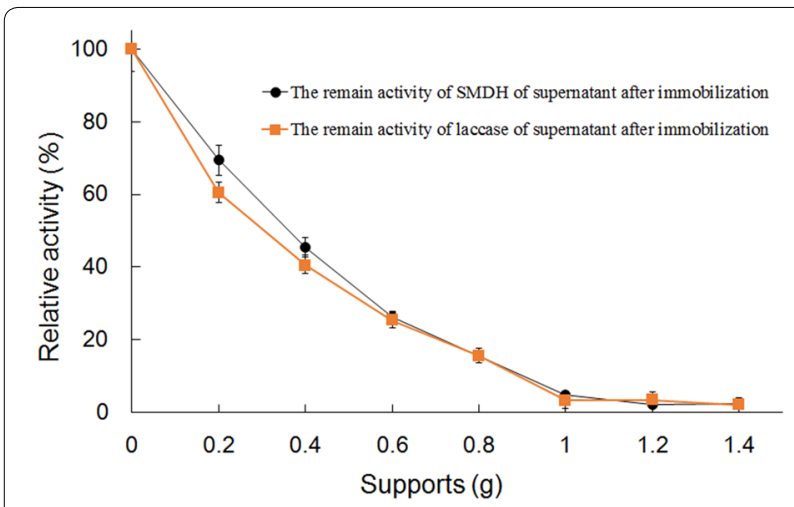

Fig. 2 Immobilization of SMDH and laccase on glutaraldehyde-activated chitosan beads. The initial enzyme activity of supernatant was taken as $100 \%$. Reactions were performed in triplicate, and error bars represented standard deviations (StDev)

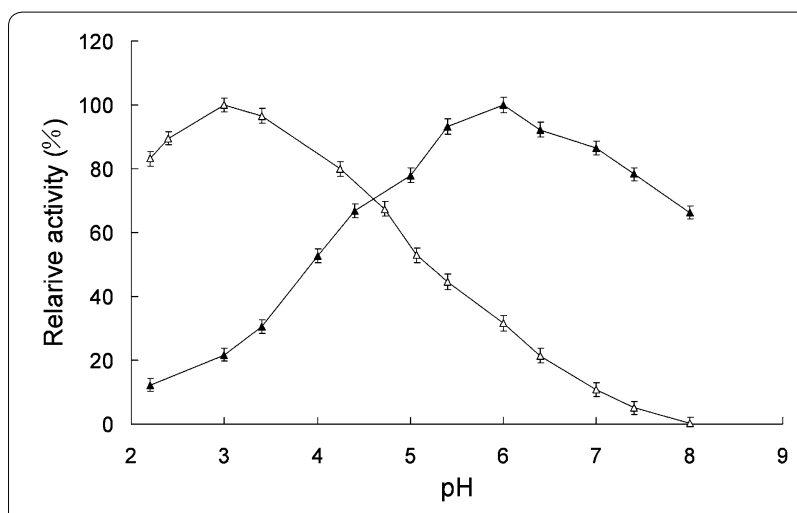

Fig. 3 Effects of pH on free and immobilized laccase activities. Open triangle indicated soluble laccase, and close triangle indicated immobilized laccase. Reactions were performed in triplicate, and error bars represented standard deviations (StDev)

enzyme had a broad $\mathrm{pH}$ range of high activity. The microenvironment of the immobilized enzyme was affected by the properties of the carrier, resulting in differences between the free and immobilized enzyme (Gupta and Kumar 2000).

The temperature dependence of the activities of the free and immobilized laccase were studied in $\mathrm{Na}_{2} \mathrm{HPO}_{4}$ citric acid buffer ( $200 \mathrm{mM}, \mathrm{pH} 6.0)$ in the temperature range $20-90{ }^{\circ} \mathrm{C}$ and temperature profiles of the free and immobilized laccase were shown in Fig. 4. It showed that the immobilized laccase had a broad temperature range of high activity. Optimum temperature was found at about $30^{\circ} \mathrm{C}$ for free laccase and $55^{\circ} \mathrm{C}$ for immobilized laccase. The support had a protecting effect at high temperatures at which enzyme deactivation took place. The conformational flexibility of the enzyme was affected by immobilization. Immobilization of laccase on chitosan beads caused an increase in the enzyme rigidity which was commonly reflected by increase in stability towards denaturation by raising the temperature (Jiang and Zhang 1993; Mohamed and Naby 1993).

The $K_{\mathrm{m}}$ of immobilized laccase for ferrocyanide was about $0.99 \mathrm{mM}$, which was greater than that of free one $(0.12 \mathrm{mM})$. An increase in $K_{\mathrm{m}}$ for an immobilized enzyme indicated that the immobilized enzyme had an apparent lower affinity for its substrate than that of the free enzyme, which may be caused by the steric hindrance of the active site by the support, the loss of enzyme flexibility necessary for substrate binding, or diffusional resistance to solute transport near the particles of the support (Çetinus and Öztop 2003).

Recently, we have shown the enzymatic properties of immobilized SMDH (Wang et al. 2014), and the immobilized SMDH showed maximum activity at $\mathrm{pH} 3.4$ and $45^{\circ} \mathrm{C}$ and its $K_{\mathrm{m}}$ value was $0.27 \mathrm{mM}$. In addition, the $K_{\mathrm{m}}$ value of the immobilized SMDH was lower than the free 


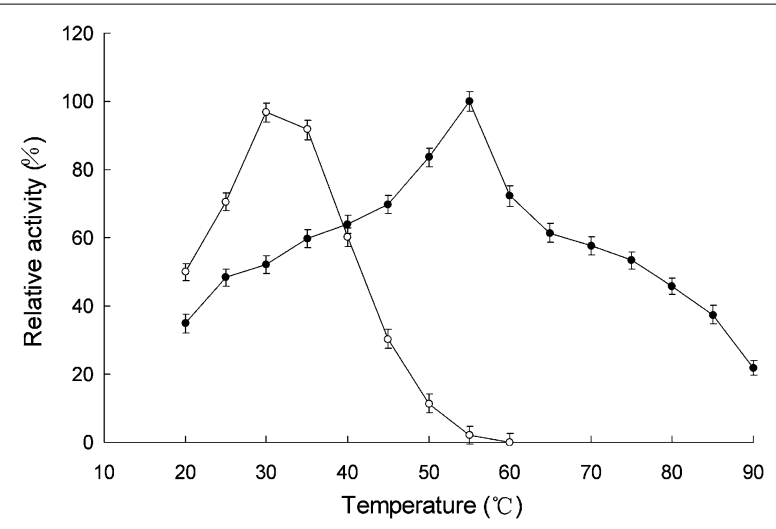

Fig. 4 Effects of temperature on free and immobilized laccase activities. Open circle indicated soluble laccase, and close circle indicated immobilized laccase. Reactions were performed in triplicate, and error bars represented standard deviations (StDev)

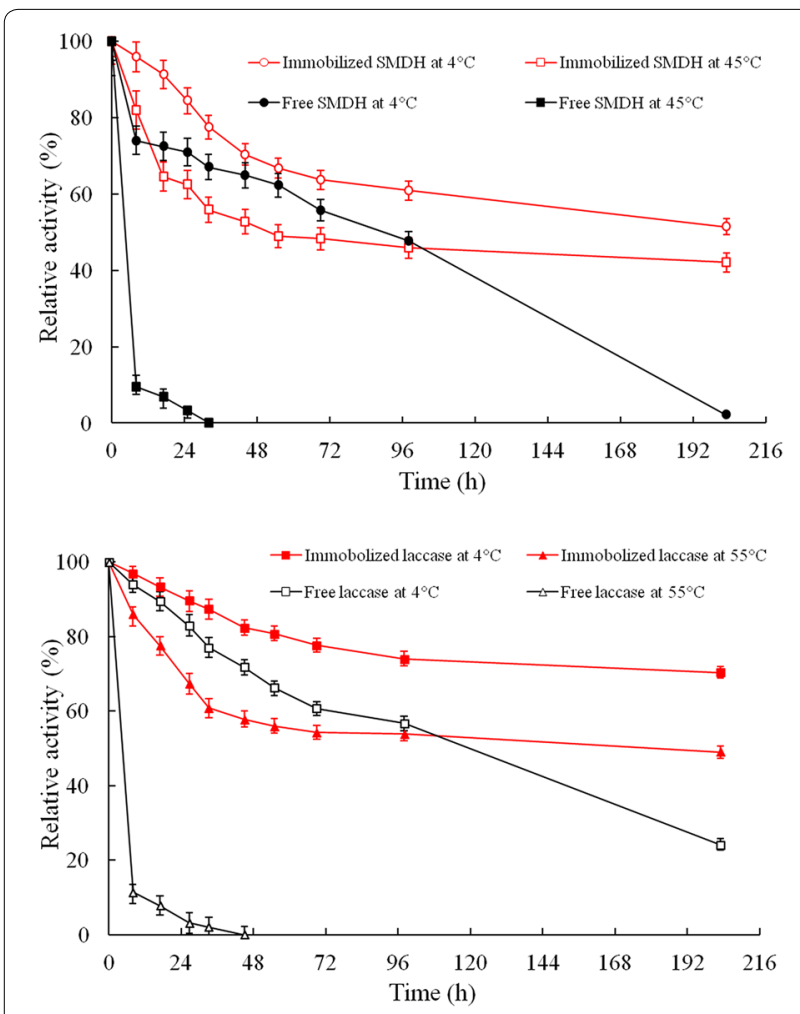

Fig. 5 Change of thermal stability and storage stability of immobilized SMDH and immobilized laccase over time. Reactions were performed in triplicate, and error bars represented standard deviations (StDev)

SMDH, and it indicated that immobilized SMDH had an apparently higher affinity for its substrate than that of the free enzyme.
Effects on the thermal stability and storage stability

Figure 5 showed the changes of thermal deactivation and storage stability of immobilized enzymes (SMDH and laccase). When incubation at their optimal temperatures for $8 \mathrm{~h}$, immobilization reduced the deactivation rate of SMDH about fivefold and that of laccase about ninefold, which suggested that the thermostability of the immobilized enzymes was significantly higher than that of the free enzymes at their optimal temperature. When storage at $4{ }^{\circ} \mathrm{C}$ for $200 \mathrm{~h}$, there was about 1.4-fold reduction of deactivation rate for immobilized SMDH and about threefold for immobilized laccase, so it showed immobilized enzymes had improved storage stability. The decrease in activity was explained as a time-dependent natural loss in enzyme activity, and this was prevented to a significant degree by immobilization (Lemainque et al. 1988). The residual enzyme activity of immobilized SMDH was about $40 \%$ and that of immobilized laccase was 55\% at their optimal temperatures for $200 \mathrm{~h}$. The residual enzyme activity of immobilized SMDH was about $60 \%$ and that of immobilized laccase was $80 \%$ after storage at $4{ }^{\circ} \mathrm{C}$ for $200 \mathrm{~h}$. In addition, the thermal stability and storage stability of the immobilized laccase were higher than the immobilized SMDH.

The high stability of immobilized enzymes at high temperatures represented that the support had a protecting effect for SMDH and laccase. When enzyme was in its free form, it presented some flexibility, which meant that its active site underwent irreversible conformational changes, causing inactivity. When it was immobilized, a more rigid form was acquired because of covalent linkages to the support. Enzymes' rigidification may lead to preservation of the enzyme properties under drastic conditions (Rodrigues et al. 2013). This stiffness decreased the enzyme's flexibility, maintaining the form of the active site, which was responsible for its activity (Silva et al. 2012).

\section{Biotransformation experiments with immobilized enzymes catalyzing}

The SMDH specially catalyzed the oxidation of S-MA to $\mathrm{BA}$, while its cofactor FMN was reduced, then the reduced FMN was regenerated by ferricyanide which was regenerated by laccase catalyzing the oxidation of ferrocyanide. Therefore, the coupling of SMDH and laccase can oxidize continuously S-MA to BA. To improve stability of the biocatalysts and reuse them easily, free SMDH and laccase were immobilized on chitosan beads.

A bi-enzymatic system consisting of free SMDH and laccase effectively catalyzed the oxidation of S-MA using a small number of redox medium and R-MA was obtained from its racemic mixture, which has been 
reported in recent study (Wang et al. 2013). Compared with the free bi-enzymatic system, the immobilized bienzymatic system showed obvious advantages, such as higher productivity, faster reaction velocity, and more stable catalytic ability. Comparison of the catalytic performance of the immobilized and free bi-enzymatic system was conducted (Table 1). The result of the free bienzyme system was reported in the recent study (Wang et al. 2013). As it was shown in Table 1, the handling capacity of substrate concentration increased threefold and the reaction velocity grew from $0.85 \mu \mathrm{mol} / \mathrm{h}$ per $\mathrm{U}$ of SMDH to $11.6 \mu \mathrm{mol} / \mathrm{h}$ per U of SMDH, which may owe to the improved stability of immobilized enzymes and the increase of mass transfer rate. However, the bienzymatic system may be inhibited by its substrate, leading to the transformation rate rising to a maximum and then descending as the substrate concentration increase, as shown in Fig. 6. Substrate inhibition was an extremely widespread phenomenon in enzyme kinetics (Reed et al. 2010). Further study will focus on the mechanism of substrate inhibition. To maximize the yield of R-MA, the reaction conditions needs to be further optimized by a kinetic model describing S-MA conversion in the bienzymatic system.

Figure 7 showed the transformation process of S-MA to $\mathrm{BA}$ using $30 \mathrm{mM} \mathrm{MA}$, which was catalyzed by the bi-enzymatic system consisting of immobilized SMDH and immobilized laccase. Analyzing Fig. 7, it was clear that S-MA was continuously oxidized to BA, and the transformation was close to complete within $10 \mathrm{~h}$. The reaction mixture after $10 \mathrm{~h}$ reaction was analyzed by HPLC, and it was found that there was no products other than BA and R-MA. The enantiomeric purity of the bi-enzymatically produced MA could be determined to be over $99 \%$ for the (R)-enantiomer by chiral HPLC. Figure 8 showed the enzyme reuse of the bienzymatic system. The enzyme activity declined gradually with more cycles. The bi-enzymatic system retained its $80 \%$ of the original activity after one cycle, while it no longer showed catalytic activity after five cycles. Due to the weak interaction of Schiff base linkage between the enzymes and supports, the enzymes can release itself from the immobilized enzymes. However, the bienzymatic system still had advantages in reuse over the free enzyme.

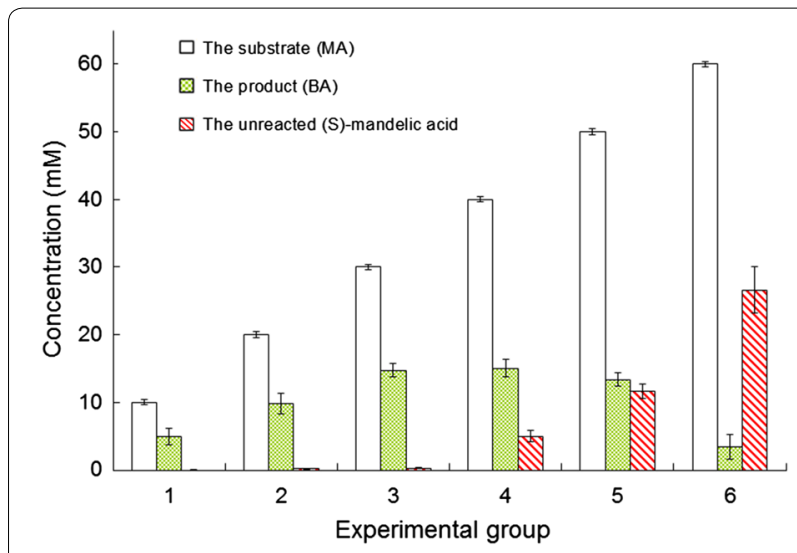

Fig. 6 Results of biotransformation reaction using different concentration of MA as the substrate catalyzed by the improved bienzymatic system after $14 \mathrm{~h}$. The reaction system contained different concentration of MA, $10 \mathrm{mM}$ potassium ferrocyanide, $1.0 \mathrm{~g}$ immobilized SMDH, $1.0 \mathrm{~g}$ immobilized laccase, and $50 \mathrm{~mL} \mathrm{Na} \mathrm{HPO}_{4}$-citric acid buffer (200 mM, pH 6.0). Reactions were performed in triplicate, and error bars represented standard deviations (StDev)

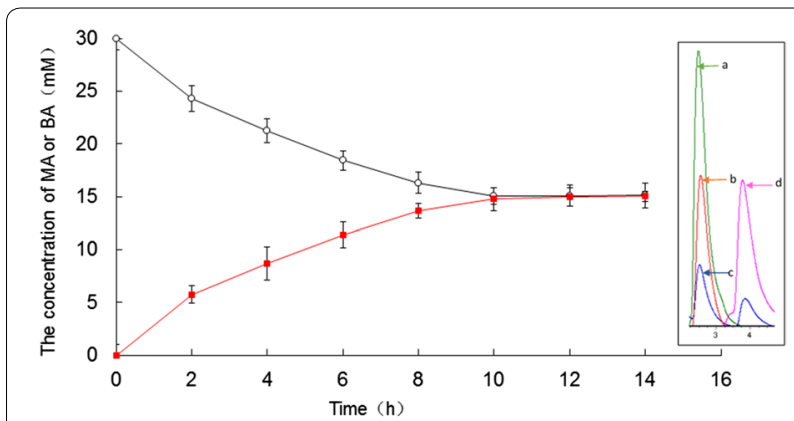

Fig. 7 Bi-enzymatic system consisting of immobilized SMDH and immobilized laccase catalyzed the conversion of (S)-mandelic acid to benzoylformic acid. Open circle indicated MA and close square indicated BA, respectively. Reactions were performed in triplicate, and error bars represented standard deviations (StDev). Inset HPLC trace of $M A$ and $B A$ at the beginning and the end of stereoselective transformation. a HPLC of MA; $\mathbf{b}$ HPLC of the beginning reaction mixture; $\mathbf{c}$ HPLC of the end reaction mixture; $\mathbf{d}$ HPLC of BA

Although the bi-enzymatic system with immobilized enzymes for the stereoselective transformation of MA was constructed, there were several challenges. Further study, more parameters would be optimized, such as

Table 1 Differences of the bi-enzymatic system with immobilized enzymes and free enzymes

\begin{tabular}{|c|c|c|c|c|c|}
\hline The bi-enzymatic system & $\begin{array}{l}\text { Total activity } \\
\text { of SMDH (U) }\end{array}$ & $\begin{array}{l}\text { Total activity } \\
\text { of laccase (U) }\end{array}$ & $\begin{array}{l}\text { Substrate } \\
\text { concentration (mM) }\end{array}$ & $\begin{array}{l}\text { Reaction } \\
\text { time (h) }\end{array}$ & $\begin{array}{l}\text { Reaction velocity } \\
(\mu \mathrm{mol} / \mathrm{h} \cdot \mathrm{U})\end{array}$ \\
\hline The free bi-enzymatic system & 49.0 & 25.0 & 10.0 & 12.0 & 0.85 \\
\hline The immobilized bi-enzymatic system & 12.9 & 6.50 & 30.0 & 10.0 & 11.6 \\
\hline
\end{tabular}




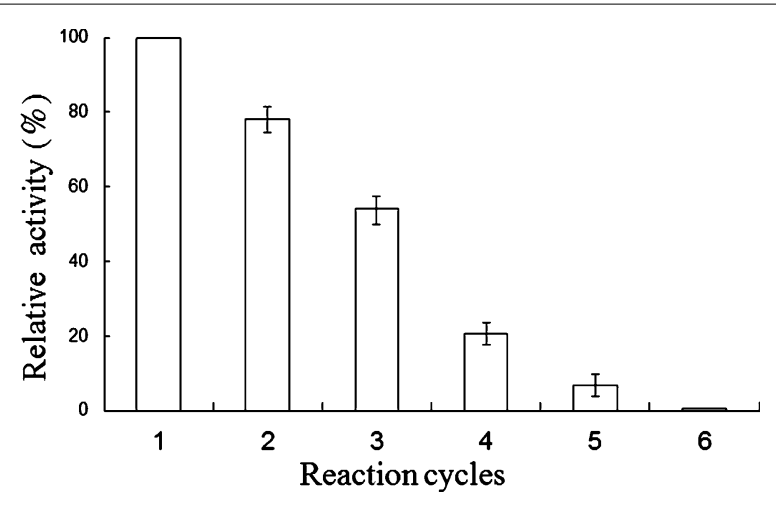

Fig. 8 Reusability of the bi-enzymatic system consisting of immobilized SMDH and immobilized laccase. Reactions were performed in triplicate, and error bars represented standard deviations (StDev)

the effect of ferrocyanide, support and immobilization method, and the co-immobilization of SMDH and laccase would be done.

\section{Conclusions}

SMDH and laccase have been successfully immobilized on chitosan. The thermal stability and storage stability of SMDH and laccase were improved by immobilization, where it was likely that immobilization prevented hydrophobic patches from aggregating. The improved properties may indicate applicability of the immobilized SMDH and laccase for the continuous bi-enzymatic reaction. Using the bi-enzymatic system with immobilized enzymes for the stereoselective transformation of MA, it showed higher productivity and faster reaction velocity than the free enzymes did. Besides, the purity of the bi-enzymatically produced R-MA exceeded 99\% using chiral HPLC.

\section{Authors' contributions}

$X C, D L L$, and $C L Y$ designed the experiments. CLY and PW performed the experiments. XC drafted the manuscript. XZ and BXB contributed to the discussion, and RFS gave important feedback on draft the manuscript. All authors read and approved the final manuscript.

\section{Acknowledgements}

Not applicable.

\section{Competing interests}

The authors declare that they have no competing interests.

\section{Availability of data and materials}

All data generated or analyzed during this study are included in this article.

Received: 24 August 2016 Revised: 26 December 2016 Accepted: 27 December 2016

Published online: 03 January 2017

\section{References}

Baminger U, Ludwig R, Galhaup C, Leitner C, Kulbe K, Haltrich D (2001) Continuous enzymatic regeneration of redox mediators used in biotransformation reactions employing flavoproteins. J Mol Catal B Enzym 11:541-550
Blank L, Ebert B, Buehler K, Bühler B (2010) Redox biocatalysis and metabolism: molecular mechanisms and metabolic network analysis. Antioxid Redox Signal 13:349-394

Çetinus S, Öztop H (2003) Immobilization of catalase into chemically crosslinked chitosan beads. Enzyme Microb Technol 32:889-894

Delanoy G, Li Q, Yu J (2005) Activity and stability of laccase in conjugation with chitosan. Int J Biol Macromol 35:89-95

Dewanti A, Mitra B (2003) A transient intermediate in the reaction catalyzed by (S)-mandelate dehydrogenase from Pseudomonas putida. Biochemistry 42:12893-12901

Gupta KC, Kumar MNVR (2000) Preparation, characterization and release profiles of $\mathrm{pH}$-sensitive chitosan beads. Polym Int 49:141-146

He Y, Xu J, Pan J, Ouyang L, Xu Y (2008) Preparation of (R)-(-)-mandelic acid and its derivatives from racemates by enantioselective degradation with a newly isolated bacterial strain Alcaligenes sp. ECU0401. Bioprocess Biosyst Eng 31:445-451

Huang H, Xu J (2006) Preparation of (S)-mandelic acid from racemate using growing cells of Pseudomonas putida ECU1009 with (R)-mandelate degradation activity. Biochem Eng J 30:11-15

Jiang B, Zhang Y (1993) Immobilization of catalase on crosslinked polymeric hydrogels-effect of anion on the activity of immobilized enzyme. Eur Polym J 29:1251-1254

Jiang D, Long S, Huang J, Xiao H, Zhou J (2005) Immobilization of Pycnoporus sanguineus laccase on magnetic chitosan microspheres. Biochem Eng J 25:15-23

Kaur I, Bhati P, Bala K, Kanwar S (2014) Effective immobilization of lipase onto a porous gelatin-co-poly(vinyl alcohol) copolymer and evaluation of its hydrolytic properties. J Appl Polym Sci 131

Kurokawa J, Asano M, Nomoto S, Makino Y, Itoh N (2010) Gene cloning and characterization of dihydrolipoamide dehydrogenase from Microbacterium luteolum: a useful enzymatic regeneration system of $\mathrm{NAD}(+)$ from NADH. J Biosci Bioeng 109:218-223

Lemainque A, Braun J, Le F (1988) Influence of polymerization of the D-amino acid oxidase on the behavior of the enzyme covalently immobilized on chitosan. Eur J Biochem 174:171-176

Li Y, Huang X, Qu Y (2013) A strategy for efficient immobilization of laccase and horseradish peroxidase on single-walled carbon nanotubes. J Chem Technol Biotechnol 88:2227-2232

Lorenz H, Sapoundjiev D, Seidel-Morgenstern A (2002) Enantiomeric mandelic acid system-melting point phase diagram and solubility in water. J Chem Eng Data 47:1280-1284

Ludwig R, Ozga M, Zamocky M, Peterbauer C, Kulbe K, Haltrich D (2004) Continuous enzymatic regeneration of electron acceptors used by flavoenzymes: cellobiose dehydrogenase-catalyzed production of lactobionic acid as an example. Biocatal Biotransform 22:97-104

Mao S, Zhang Y, Rohanl S, Ray AK (2012) Chromatographic resolution and isotherm determination of (R, S)-mandelic acid on Chiralcel-OD column. J Sep Sci 35:2273-2281

Mohamed A, Naby A (1993) Immobilization of Aspergillus niger NRC 107 xylanase and $\beta$-xylosidase, and properties of the immobilized enzymes. Appl Biochem Biotechnol 38:69-81

Reed M, Lieb A, Nijhout H (2010) The biological significance of substrate inhibition: a mechanism with diverse functions. BioEssays 32:422-429

Rodrigues R, Ortiz C, Berenguer-Murcia Á, Torres R, Fernández-Lafuente R (2013) Modifying enzyme activity and selectivity by immobilization Chem Soc Rev 42:6290-6307

Silva J, Macedo G, Rodrigues D (2012) Immobilization of Candida antarctica lipase $B$ by covalent attachment on chitosan-based hydrogels using different support activation strategies. Biochem Eng J 60:16-24

Takahashi E, Nakamichi K, Furui M (1995) R-(-)-Mandelic acid production from racemic mandelic acids using Pseudomonas polycolor IFO 3918 and Micrococcus freudenreichii FERM-P 13221. J Ferment Bioeng $80: 247-250$

Thurston C (1994) The structure and function of fungal laccases. Microbiology 140:19-26

Tulashie S, Lorenz H, Seidel-Morgenstern A (2010) Solubility of mandelic acid enantiomers and their mixtures in three chiral solvents. J Chem Eng Data 55:5196-5200

Wang P, Yang J, Jiang L, Feng J, Yang C, Li D (2013) A bi-enzymatic system for efficient enantioselective bioconversion of racemic mandelic acid. J Mol Catal B Enzym 94:47-50 
Wang P, Li D, Yang J, Jiang L, Feng J, Yang C, Shi R (2014) Immobilization of (S) mandelate dehydrogenase and its catalytic performance on stereoselective transformation of mandelic acid. J Taiwan Inst Chem Eng 45:744-748 Zhang Z, Xu J, He Y, Ouyang L, Liu Y, Imanaka T (2010) Efficient production of (R)-(-)-mandelic acid with highly substrate/product tolerant and enantioselective nitrilase of recombinant Alcaligenes sp. Process Biochem 45:887-891

Zhang Z, Pan J, Li C, Yu H, Zheng G, Ju X, Xu J (2014) Efficient production of (R)(-)-mandelic acid using glutaraldehyde cross-linked Escherichia coli cells expressing Alcaligenes sp. nitrilase. Bioprocess Biosyst Eng 37:1241-1248

\section{Submit your manuscript to a SpringerOpen ${ }^{\circ}$ journal and benefit from:}

- Convenient online submission

- Rigorous peer review

Immediate publication on acceptance

- Open access: articles freely available online

- High visibility within the field

- Retaining the copyright to your article 